\title{
(C) OPEN ACCESS \\ Withdrawal of ventilation at the patient's request in MND: retrospective exploration of the ethical and legal issues that have arisen for doctors in the UK
}

\author{
Kay Phelps, ${ }^{1}$ Emma Regen, ${ }^{1}$ David Oliver, ${ }^{2,3}$ Chris McDermott, ${ }^{4}$ \\ Christina Faull ${ }^{5,6}$
}

- Additional material is published online only. To view please visit the journal online (http://dx.doi.org/10.1136/ bmjspcare-2014-000826)

For numbered affiliations see end of article.

\section{Correspondence to} Dr Christina Faull, LOROS: The Leicestershire and Rutland Hospice, Groby Road, Leicester LE3 9QE, UK; Christinafaull@ loros.co.uk

Received 18 November 2014 Revised 18 March 2015

Accepted 23 June 2015 Published Online First

11 September 2015
To cite: Phelps K, Regen E, Oliver D, et al. BMJ Supportive \& Palliative Care 2017:7:189-196.

\section{ABSTRACT}

Background Ventilatory support has benefits including prolonging survival for respiratory

failure in motor neurone disease (MND). At some point some patients may wish to stop the intervention. The National Institute of Health and Care Excellence (NICE) guidance recommends research is needed on ventilation withdrawal. There is little literature focusing on the issues doctors encounter when withdrawing ventilation at the request of a patient.

Aim To identify and explore with doctors the ethical and legal issues that they had encountered in the withdrawal of ventilation at the request of a patient with MND.

Method A retrospective thematic analysis of interviews of 24 doctors (including palliative care, respiratory, neurology and general practice) regarding their experiences with withdrawal of ventilation support from patients with MND. Results Respondents found withdrawal of ventilation at the request of patients with MND to pose legal, ethical and moral challenges in five themes: ethical and legal rights to withdrawal from treatment; discussions with family; discussions with colleagues; experiences of legal advice; issues contributing to ethical complexity. Though clear about the legality of withdrawal of treatment in theory, the practice led to ethical and moral uncertainty and mixed feelings. Many respondents had experienced negative reactions from other healthcare professionals when these colleagues were unclear of the distinction between palliation of symptoms, withdrawal of treatment and assisted death.

Conclusions Legal, ethical and practical guidance is needed for professionals who support a patient with MND who wishes to withdraw from ventilation. Open discussion of the ethical challenges is needed as well as education and support for professionals.

\section{BACKGROUND}

Motor neurone disease (MND) is a progressive neurological condition which primarily affects motor neurons leading to skeletal muscle weakness including respiratory muscles. Most deaths in MND are due to respiratory failure. Using non-invasive ventilation (NIV) support can improve quality of life, symptoms and survival ${ }^{1}{ }^{2}$ and UK guidance from the National Institute of Health and Care Excellence (NICE) supports its use. ${ }^{3}$ NIV can very effectively support ventilation, often for many months. ${ }^{4}$ A few patients may choose ventilation via tracheostomy (TV) if NIV fails. In the UK the use of NIV has increased over the past 10 years. ${ }^{5}$ The number of patients on TV is unknown.

Neurological deterioration is relentless for patients despite ventilation and patients may eventually reach a point at which they cannot move or communicate ('locked in'). ${ }^{6}$ Many patients also develop cognitive change which can affect their ability to make decisions. ${ }^{7}$

Although getting used to NIV can be problematic $^{8}$ with perseverance over a few weeks many patients report an improved quality of life. ${ }^{19}$ Longitudinal studies of patient experience through the full course of their illness are lacking but a recent study of five patients who had used NIV for more than 12 months has shown that even for those that adapt well to using NIV and are positive about its 
value for them, the commonest negative psychological experience was related to dependence. ${ }^{10}$

It appears from our collective clinical experience that the majority of patients using NIV in the UK die while still using it. However, some patients who are dependent on NIV, and some on TV, will wish to stop because they can no longer tolerate it or because of deterioration in other factors impacting on their quality of life. Some may make a written statement with respect to withdrawal in advance of their losing the ability to communicate or other reason for loss of capacity. ${ }^{11}$

We have previously reported on our questionnaire study with doctors in palliative medicine in which we gained an overview of the magnitude and frequency of the emotional, practical and ethical issues that may arise in this context. ${ }^{12}$ We have explored these issues in more depth with this qualitative study. This paper reports on one theme which has emerged from the data: the ethical and legal challenges experienced by doctors who have withdrawn ventilation at the request of a patient.

\section{METHODS}

This was a retrospective qualitative interview study. Doctors were asked to talk about the most recent and other most notable patients with whom, at the request of the patient with MND, they had withdrawn ventilation. A topic guide, developed from the scoping study ${ }^{12}$ was utilised flexibly to explore each doctor's experiences in detail.

\section{Participants and data collection}

Doctors, across England, Wales and Scotland, who had withdrawn ventilation at the request of a patient with MND within the past 5 years, were invited to participate in a one to one interview in person or by telephone as they preferred.

A multifaceted email recruitment strategy was employed to approach participants:

Directly to doctors

- Members of the Association for Palliative Medicine of Great Britain and Ireland (APM) who had responded to the scoping study indicating their willingness to participate.

- APM members of the advanced neurological disease specialist interest forum.

Indirectly via a network

- MND Clinical Studies Group within the Dementia and Neurodegenerative Diseases (DeNDroN) research network for England and Wales.

- Regional Care Advisors for the Motor Neuron Disease Association who then contacted doctors they knew had been involved with such patients.

- Motor Neuron Disease Regional Care Centre clinical directors and coordinators.

- Lane Fox Unit Guy's and Thomas', Papworth and Kings College Hospitals specialist respiratory teams leads.
- British Thoracic Society home ventilation-UK group.

Everyone contacted by email was asked to pass this on to other doctors who they thought might be interested.

R\&D approval was sought for those who contacted the principle investigator (CF) to discuss participation and subsequently full participant information was shared. Consent was taken in person before face-to-face interviews or by phone with subsequent email of written consent.

Purposive sampling was used to achieve the broadest diversity of medical specialties. This resulted in three palliative care doctors not being interviewed but all other volunteers being recruited.

\section{Data analysis}

The interviews were audiorecorded and transcribed and interviewers (ER and KP) maintained reflexive diaries. Data from transcripts were analysed by constant comparison based on grounded theory to identify themes. ${ }^{13}{ }^{14}$ Open coding: (ER and KP) summarised the ways that participants talked about the issues and processes that mattered. These codes were progressively focused into broader categories, forming the initial coding frame, further shaped by Steering Group discussion. The coding frame was systematically applied by KP and ER, discussing situations of uncertainty of coding and using NVivo V.9 software, and continuously developed in response to new information.

The purpose of analysis was to illustrate the breadth of experience, opinions, views and practices of the study participants, identify challenges and ways to improve the experiences of all those involved in ventilation withdrawal. The themes emerging from the interviews relating to the ethics and legality of ventilation withdrawal are illustrated in the table 1.

No new themes were elicited after 15 interviews but each interview and each patient discussed within an interview conveyed a uniqueness of context and nuance.

\section{Ethical concerns}

The study was approved by the East Midlands Derby Research Ethics Committee reference 11/EM/0131. All participants were provided with participant information sheet that explained their involvement in the study.

\section{FINDINGS}

Twenty four doctors (15 palliative medicine labelled A1-A15, 1 neurologist labelled B1, 4 anaesthetist/ respiratory labelled C1-4 and 4 GPs labelled D1-4) were interviewed, 5 by telephone and 19 face to face. Sixteen had withdrawn NIV only, five had withdrawn TV only, and three had withdrawn both NIV and TV. Nine respondents had been involved with more than one patient. 
Table 1 Legal and ethical themes emerging from interviews with doctors

\begin{tabular}{|c|c|}
\hline Main theme & Subthemes \\
\hline $\begin{array}{l}\text { Theoretical knowledge of } \\
\text { ethics and the law }\end{array}$ & $\begin{array}{l}\text { Is withdrawal ethical and legal } \\
\text { Is it unethical or illegal not to withdraw } \\
\text { Under what circumstances is it legal and } \\
\text { ethical to withdraw } \\
\text { What if patient is not close to death }\end{array}$ \\
\hline Ethical and legal practice & $\begin{array}{l}\text { Experience and knowledge } \\
\text { Discussions of ethics and the law with } \\
\text { colleagues, patients and families, } \\
\text { including disagreements. } \\
\text { Palliation of symptoms-what is legal } \\
\text { External scrutiny, the need to document } \\
\text { practice and work in teams for legal } \\
\text { security } \\
\text { Protecting the family ethically, morally and } \\
\text { legally }\end{array}$ \\
\hline $\begin{array}{l}\text { Does withdrawal feel ethical } \\
\text { and moral }\end{array}$ & $\begin{array}{l}\text { Felt right } \\
\text { Felt uncomfortable or wrong } \\
\text { Fear of misinterpretation as assisted death } \\
\text { Ethical and moral burden }\end{array}$ \\
\hline $\begin{array}{l}\text { Ethical and legal } \\
\text { recommendations }\end{array}$ & $\begin{array}{l}\text { Need for legal and ethical guidance } \\
\text { Need for professional education }\end{array}$ \\
\hline
\end{tabular}

The setting for withdrawal included home (the most common for TV), hospice (the most common for NIV), acute hospital, community hospital and one care home. Such events were rare but extraordinarily memorable with explicit detail of aspects recalled from several years previously. The emotionality and the tensions of the situation were especially vivid.

Box 1 Reflections on the patient's right to have ventilation withdrawn

A05: ... and if a patient has an intervention that they do not want and even if they're asking for removal of it and that's going to bring life to an end, they have the absolute right to do that.

A09: ... you need to be careful not to bring your own resistance because this is unusual or difficult. It has an impact. In a sense it's easier to do nothing than it is to say well we'll withdraw it.

A17: ... if the patient is clearly saying and they are autonomous and competent to say 'I want my Nippy removed', then we are following their wishes. If they want to do that because they want their life to end, well clearly they probably do want their life to end, because once you tell them well if we stop the Nippy you'll die, then clearly that's what they want. So in a way yes maybe we are fulfilling their wishes to die. You end up talking yourself in circles don't you, but that's OK because they can refuse life prolonging treatment .... So I think it feels slightly uncomfortable but I still think it's the right thing to do.

B03: The ethical issue actually is refusing to do it, that would be an act of great wickedness and cruelty.
Discussions of ethics, morals and legality went hand in hand. It was felt that the ethics were complex: while ethical theory can be clear, applying ethics to a clinical situation was not straightforward and was for some professionally and personally burdensome.

A11 ... the discussion around the ethics, it's messy. Ethics is messy by the bed side, that's the thing. ... I'm absolutely clear on the ethics of it, there's no doubt that was the right thing to do. It was just at the time and in that slightly surreal sort of circumstances, it just felt very, very strange and uncomfortable.

\section{The patient has a legal right to withdrawal from treatment}

The patient's ethical and legal right to refuse or withdraw from treatment even when this may hasten their death was affirmed by all participants. Continuation of treatment when a patient did not wish it was considered wrong. However, doctors reflected on the potential that there was to override this right where the patient still had considerable functional abilities; the patient's prime wish was to cease living; or because it was much easier not to carry out the patient's wishes than it was to withdraw ventilation (box 1).

Doctors used a clear framework to decide whether each individual case was ethical and legal in practice. This was that withdrawal from treatment was a sustained wish of the patient; that the patient had capacity and was not depressed; that the patient had made an informed choice and was not influenced unduly by others; and the patient was aware of the consequences of withdrawal. Doctors went to considerable lengths to establish these features with patients. Working with this framework could be very challenging due to significant difficulties in communication caused by MND (box 2).

\section{Discussions with family}

A key part of the doctor's work was discussing and explaining the legal and ethical context with patients

Box 2 The complexity of assessment of wishes and capacity

A04: Communication with him was very difficult because by this stage he could just move his eyes left and right so there were quite a lot of yes/no questions. We used the alphabet board as well. But it was very clear that he wanted to have it removed ... he didn't feel depressed, he just felt that his quality of life had deteriorated as his illness had progressed and he wanted to be allowed to die naturally from that.... I was very happy that his wish was clear and sustained and he had capacity.

A16: I think my worry was she'd become incredibly depressed and had therefore decided to stop it, but once we'd established that, I felt perfectly comfortable. 
and families. Respondents felt a need to gain agreement from and within the family because it felt 'easier' to enact decisions based on consensus. These discussions were also to mitigate the risk of legal action or exposure in the media. Such conversations could be difficult with some families wanting to discuss other issues such as euthanasia and physician assisted suicide (box 3).

\section{Discussions with colleagues and coping with the differing views of colleagues}

All respondents talked about the importance of open discussion about ethics and legality with colleagues. This could require a considerable amount of time and effort. The circumstances of every case required exploration and the rationale needed to be transparent, articulating the legal and ethical framework and demonstrating that the necessary criteria were in place (box 4). Fostering consensus and listening to dissent were important strategies and enhanced the doctor's own ethical learning.

Several participants experienced disagreements with healthcare colleagues who considered ventilation withdrawal to be ethically or legally unacceptable and different from withdrawal of other treatments. Some colleagues saw it as assisted suicide. Doctors perceived that the elements of this concern were: the withdrawal of life sustaining treatment was seen as the cause of death for the patient (rather than the MND); that the drugs used to manage symptoms were perceived as shortening life; that the close timing of stopping treatment and death occurring was perceived as causality; differing opinion on validity of advance decisions (box 5).

This caused stress and fear for some of the professionals involved, and in more than one case a court

\section{Box 3 The complexity of discussions with family}

A16: I think some of them found it more difficult than others and I think managing the expectations of 4 adults with different views, that was quite difficult, and some of them were very, just emotional about the ethics of it and whether it was the right thing.

B03: Her partner, it was much more complicated. I met him on a number of occasions with her permission and it became clear that his agenda was a little different and was very much about controlling things, including talking about actively ending her life in all sorts of ways. He wanted to discuss euthanasia and all this sort of stuff, so it was challenging professionally to do that.

A16: Probably the most challenging thing of that intervention was the discussions with the family, because they'd got themselves in a real tangle about whether taking the mask off was shortening her life in any way hearing. This professional reluctance sometimes had an influence on choice of setting for patients and required consideration of how to handle staff discomfort or refusal to take part on the grounds of conscience. Occasionally the patient did not have their request fulfilled. Wider discussion and education among professionals to clarify the legal and ethical position of withdrawal of ventilation was felt to be needed.

Most respondents had discussed the situation with a considerable number of peers, and palliative medicine consultants often had a key role in articulating the ethico-legal framework. The need for greater support for doctors who are responsible for the care of the patient was highlighted (box 6). First to discuss and clarify the ethical and legal issues; second to give professional backup should questions be raised after the withdrawal; and third to share the emotional impact. Because of the rarity of the situation and the lack of expertise in ethico-legal matters some thought that formal affirmation of a clinical ethics committee would be very valuable and the two respondents who had experience of this had found it very positive.

\section{Experiences of legal advice}

The majority of doctors, sure of the legality of the care, did not seek legal advice or guidance. Some did consult with their personal medico-legal advisors or Trust legal department and many received clear

Box 4 Educating colleagues and facilitating safe team working

A04: I wanted to get all the nursing staff together because I didn't want any of them to feel that what we'd done was, well, something it wasn't and wanted to make sure that they were all happy with what we were doing and give them an opportunity to ask any questions.

A07: Part of making it, sort of, almost emotionally and psychologically safe for the staff and for me as being the consultant was to actually get some agreement quite early on in terms of the framework of ethics and law that we're working under.

D10: It's reinforced for me the value of teamwork where there are difficult ethical issues to tackle. The value of sharing opinions, not just with other doctors but with other professionals, family, lay people. That is what makes an ethical society I think is the shared values.

A13: I don't think I was asking colleagues or discussing it with colleagues because I wanted their approval and to make sure that they thought it was the right thing to do, because I knew it was the right thing to do, I didn't have any doubts about that at all, but it was just making sure that their views were consistent with mine... 


\section{Box 5 Working with professional disagreement}

B03: What killed that patient was her disease not a midazolam injection. So I went to talk to them and we talked it all through and I don't think I ever came away feeling I totally understood what their problem was. It simply was out of their comfort zone because they have a certain view of what they do and this seemed to be just at the boundary, it seemed to be to them a little bit more active than they normally do.

A14: A lot of it felt like education rather than a really deep ethical debate about the right to life.

A02: I think the difficulty is if you integrally believe something, like I intrinsically feel that it's the disease and not your action that's making them die, if they think that action is what equals you killing them or them dying, then that intrinsic feeling that you have is very difficult to shift that, even through rational thought and discussion.

A11 They just didn't feel they were geared up to be dealing with that sort of ethical issue. Everyone I think in it was worried about what kind of death he'd have. The pressure was, this would be far better done at the hospice if he wants this done. But he didn't want that, he wanted to be at home.

A04 The plan was for him to come in and have ventilation withdrawal and a lot of the nurses were very against that. They were concerned that it was euthanasia. In the end, the patient actually died before the ventilation was withdrawn.

advice. However, some respondents found this contact promoted an even greater sense of vulnerability and did not enhance patient care. Some were advised not to be involved in the withdrawal (box 7).

\section{Issues contributing to ethical complexity}

Doctors reflected on the issues which contributed to the ethical complexity of the situation (box 8).

\section{Cause and effect}

Because of the direct link between removal of ventilation and death and because of the closeness in time of action and effect, respondents felt that the patient died because of something they did. Doctors had to reconcile their intensive involvement in the patient's care with a sense of responsibility or causation of dying.

\section{Planning when to withdraw treatment (and to die)}

A consequence of the immediacy of death subsequent to withdrawal meant that patients, families and professionals were aware that the plan for withdrawal was also setting the time for death. This was unfamiliar and the aspect most in tension with practices aimed directly at ending life. An added ethical complexity
Box 6 The need for more professional support for the doctor leading the patient's care

A09: I suppose my feeling was I didn't want one professional to be left being the one who did it. If you're one member of staff and you are the one switching off the machine, then I think that's difficult.

A04: And I think that was a huge part of my role was supporting people to do that (withdrawal of ventilation) and saying 'This is O.K, This is the right thing to do'.

D06: I spoke with a Palliative Medicine consultant on a number of occasions about it and we discussed the legal framework around it; that we were withdrawing a life preserving treatment if you like rather than actively ending somebody's life as such.

D10: But actually it was just her (Palliative Medicine consultant) and me I think and his wife round the bedside that time and I've got to say that was really helpful. And she said -, she made the ethics clear, that it's his decision to remove the mask and he knows the consequences.

A13 He needed reassurance from me a fellow doctor; he needed reassurance from his clinical partners and he needed reassurance from his defence union that what we were doing was within the bounds of legality.

A15: If you have somebody else who's done it and been through it; how much did you give and what was the result. That sort of support I think would always be helpful.

acknowledged by doctors was that some patients were explicitly asking for the treatment to be stopped because they did not want to continue to live or face further loss of ability.

Breathing is fundamental

It was thought that removal of ventilation may feel ethically different than removal of other treatments due to the fundamental nature of breathing to stay alive.

\section{Rarity}

The relative rarity of the event itself, and that this involved the very unusual situation for most doctors of stopping a machine, was reflected on by respondents. That a patient requested it to be stopped contrasted with most other circumstances where machines are stopped because the clinicians decided that the intervention was no longer helpful.

\section{A conscious patient}

Withdrawal of treatment, leading to death, from a patient who was alert, often able to communicate and who had no other vital organ disease making them unwell caused considerable soul searching. 


\section{Box 7 Experiences of legal advice}

A11 There'd been all sorts of concerns about well 'do we need to tell the coroner in advance of this?', 'do we need to inform our medical defence organisation in advance of this?' and a lot of angst about the legality of it. And the advice had been from the defence organisation get on and do it.

A14: I rang the defence organisation sort of saying, they're not particularly palliative so they were saying 'oh you might want to get a second opinion'. So I thought I'd better had in case this daughter went to the Police. -and I did feel bad because I did drag it out another $24 \mathrm{~h}$.

C20: The defence organisation was useless actually. I know more about the ethics of this than they did.

D10. The defence organisation said that it would be unlawful to remove the mask purely for the purpose of hastening his death. And that was worrying because, well, effectively, we were going to remove the mask and we knew that the consequences were going to be that he'd die of natural causes. And so that was really a rather unhelpful way of putting it. The second point they made was that it was not unlawful to respect his refusal to accept treatment, providing he is of sound mind. And then they said it would be prudent to involve a palliative care consultant and a neurologist to explore alternatives. And they made a great thing of the fact that how do you know he's got MND? How do you know that there's no cure? Hadn't you better keep searching for a cure? ....

D18: The family come to me because I'm their GP. They ring me up and say he wants his nippy removed. I get people like him (defence organisation) telling me 'You're not qualified, you shouldn't be involved.' and I get other people speaking to me saying 'You're his GP, you are responsible for every element of his care. If you don't turn off his nippy and he doesn't consent to it, you're assaulting him.' I asked the PCT for legal help, I asked the PCT for a lead and I just got passed round the houses and it got thrown back in my court. The person they did say should lead it didn't step up.

\section{Palliating symptoms and relieving suffering}

Respondents had experienced anxieties about the ethics related to the use of medication as the ventilation was withdrawn. Some felt that as the patient's death was imminent, the amount of medication was irrelevant as long as the patient experienced no suffering. Others felt concerned that they were not seen to hasten the patient's death with medication.

\section{DISCUSSION}

Our research is the first to explore in depth the experiences of doctors involved in the withdrawal of ventilation at the request of a patient with MND. This is a rare event but the work draws on interviews with
Box 8 The issues identified as promoting ethical complexity

A08 it feels that one moment you've got a patient there who's alive and able to do things and have some communication with you about themselves and then it feels as though through my action, 10 min later they're dead.

A15 Although it's withdrawing artificial treatment, there's a very clear causal link with turning off the machine and dying a short while afterwards.

A14: I was setting a time. I was agreeing with the wife the time at which he would die and eeuurrgh it was horrible, but it wasn't what we were doing, it was-'I'll see you at 11 and we'll do it then.' Of course you've got to. They wanted to be with him. They needed to know when we were going to do it.

C12: I think it's harder to stop something, some way of giving people oxygen or helping them to breathe more easily unless they're very very unwell.

A13 people who are on kidney dialysis and that's a machine that's keeping their kidneys going, they elect to stop having dialysis and they'll die usually fairly quickly, usually within days of stopping dialysis. But breathing's perhaps a bit more emotional so anything to do with the heart or breathing might be a bit more emotional for people.

A16: I think it is different because it's much more immediate and breathing seems one of those very elemental things to us.

A08: There's a strange illusion of, perception of gosh I'm giving them a drug that's causing them to die. Even though rationally one knows that that's not the case.

C20: The anxieties that people have that they will be perceived as giving patients drugs to end their lives.

A05: it did feel very strange going back later on with an intravenous canula for administration of midazolam to avoid respiratory distress. Even though I knew that we'd done everything ethically and legally correctly, it just inevitably conflicts with feelings of euthanasia and assisted suicide.

24 doctors with more than 30 patients. All narratives described huge complexity in the reality of applying law and ethics to real life socioclinical contexts.

The right of a patient who has capacity for the decision to refuse treatment and for symptoms of withdrawal to be managed effectively is clear in case law ${ }^{15}$ and in the medical code of conduct in the UK. ${ }^{16}$ All our participants understood these facts and their role was often to help both families and colleagues understand them too. Most often this led to consensus. In some instances, however, people's individual perspectives were not reconcilable. These tensions in end of life decision-making are echoed in other work which explores decision-making ${ }^{17} 18$ but no work to our 
knowledge has previously sought to understand the experiences of professionals themselves. Gannon has previously described the impact of consideration of the request of a patient to withdraw ventilation within a hospice setting and identified similar themes that raise ethical tensions within professional hospice teams. ${ }^{19}$ LeBon and Fisher reported on withdrawal of TV on a patient in the community and found that the legal and ethical distinctions between euthanasia, assisted suicide and withdrawing active treatment following a request from a competent patient may remain blurred for many clinicians and require a clear explanation. $^{20}$

While it may be thought that advance care planning offers a way to reduce ethical complexity our findings have shown that even when patient wishes are fully articulated and documented the enactment of these wishes in relation to withdrawing treatment and managing symptoms may not be straightforward.

Because the discomfort and potential impact of the situation was so great may participants sought further advice from colleagues, medical defence organisations and ethics committees. In some cases far from supporting patient care these discussions increased the complexity and anxiety for professionals and delayed the response to the patient. This situation is untenable and the Association for Palliative Medicine has produced a position statement on this specific area of care (see online supplementary appendix 1 ).

The complex ethics in the relatively common scenario of withdrawal of ventilation in intensive care have been discussed. ${ }^{21} 22$ Two key features of withdrawal of ventilation at the request of a patient with MND make it different. First, it is the patient asking for it to be stopped, not a decision made on the basis of the failure of medical treatment. Where similar situations arise in intensive care this is acknowledged as increasing ethical (and practical) difficulty. ${ }^{23}$ Second the patient is conscious and often communicating although some will have lost this function. Tweeddale has discussed how while explicit direction by a patient should make care more straightforward, in practice this may raise tensions professionals may not be consciously aware of. ${ }^{18}$

For many of our respondents even though the ethical and legal arguments had been discussed and checked and documented, withdrawal of ventilation still felt uncomfortable. The BBC Radio 4 Inside the Ethics Committee has helpfully explored the roots for such ambiguity. ${ }^{24}$ The extraordinariness of planning a time for withdrawing a treatment which will closely be followed by death is a key element of this. Additionally perhaps, because the clinician is aware the patients reasoning behind withdrawal of ventilation may be based on the desire to end their lives, the removal can feel like assisted suicide. In these circumstances then, the arguments of some clinicians that it felt 'wrong', even though it is ethically, morally and legally 'correct' has an importance in ensuring care practice is within the boundaries of Good Medical Practice. ${ }^{25}$

Doctors felt that experience, knowledge, open discussion and documentation were all needed in each case to ensure the safety of everyone involved, not least the patient. Experience around withdrawal of treatment and/or end of life care helped a professional to understand the ethical and legal issues and feel confident in their practice. It was thought that healthcare professionals who lacked the relevant experience may be less likely to understand the ethics and legality of withdrawal and consider it to be assisted suicide. Many participants had engaged in protracted discussions with colleagues about whether or not assisting a patient to withdraw from their ventilation was assisted death, and some felt that this is an area which requires debate and specific clarification. There was a great deal of concern that if other healthcare professionals could view withdrawal as assisted death, then the wider public would also lack understanding. It may not have been that they did not understand the arguments, however, but that to them it felt morally, if not legally, wrong. A further risk is that patients potentially do not receive the end of life care they wish for if staff refuse to participate, or that patients cannot die in their preferred place of death.

\section{CONCLUSION}

The experiences of doctors in our study was that the ethical and legal issues around withdrawal of ventilation at the patient's request while ostensibly straightforward, in practice lead to highly complex discussions and emotions. This may impact on patient care. Many professionals need more education and support including the provision of clear and consistent advice. This would not only support clinicians but would also protect patients and their families from the agonies of indecision and ambiguity.

Robust advance care planning processes which enable patients to share their choices may help to reduce ambiguity but are not a failsafe unless professionals act in accordance with the legal frameworks underpinning advance decision-making. The role of Palliative Medicine doctors is often to help patients, families and colleagues understand and work with the ethical and legal framework as well as to provide effective symptom management. This study might suggest that a greater integration of palliative medicine with neurology services has potential to improve the experiences of all involved and the outcomes for patient and families.

\section{Author affiliations \\ ${ }^{1}$ Department of Health Sciences, College of Medicine, Biological Sciences and Psychology, \\ University of Leicester, Leicester, UK \\ ${ }^{2}$ Wisdom Hospice, Rochester, Kent, UK}


${ }^{3}$ Centre for Professional Practice, University of Kent, Chatham, UK

${ }^{4}$ Department of Neurology, Sheffield Institute for

Translational Neuroscience, University of Sheffield, Sheffield, UK

${ }^{5}$ LOROS: The Leicestershire and Rutland Hospice, Leicester, UK

${ }^{6}$ Honorary Professor DMU-LOROS Centre for the

Promotion of Excellence in Palliative Care,

De Montfort University, Leicester, UK

Acknowledgements The authors would like to thank the participants for their honesty and responsiveness. Ms Idaliza Nukis has provided immense administration for the study including the substantial work required to navigate the R\&D approvals across 23 sites.

Contributors CF designed and lead the study, was involved with recruitment and data interpretation and in drafting the paper. $\mathrm{KP}$ and ER undertook all consenting, data collection and analysis and were involved in drafting of the paper. CM and DO aided recruitment and were involved with data interpretation and drafting the paper.

Funding The study was mostly funded by LOROS, Hospice Care for Leicestershire and Rutland with additional funding from the MNDA Grant Faull/Apr12/6389 for the interviews focusing on withdrawal of TV.

Competing interests DO was a member of the Guideline Development Group for the NICE Clinical Guideline on NIV in MND Guideline 105 . $^{3}$

Provenance and peer review Not commissioned; externally peer reviewed.

Data sharing statement Raw anonomised interview data will not be shared as we did not seek consent from participants beyond its use by the research team. We believe that to do so may have put recruitment at risk. Synthesised anonomised data might be shared subject to compliance with the consent from the participants.

Open Access This is an Open Access article distributed in accordance with the Creative Commons Attribution Non Commercial (CC BY-NC 4.0) license, which permits others to distribute, remix, adapt, build upon this work noncommercially, and license their derivative works on different terms, provided the original work is properly cited and the use is non-commercial. See: http://creativecommons.org/licenses/by$\mathrm{nc} / 4.0 /$

\section{REFERENCES}

1 Bourke SC, Tomlinson M, Williams TL, et al. Effects of non-invasive ventilation on survival and quality of life in patients with amyotrophic lateral sclerosis: a randomised controlled trial. Lancet Neurol 2006;5:140-7.

2 Piepers S, van den Berg JP, Kalmijn S, et al. Effect of non-invasive ventilation on survival, quality of life, respiratory function and cognition: a review of the literature. Amyotroph Lateral Scler 2006;7:195-200.

3 National Institute for Health Care Excellence. Clinical Guideline 105: Motor Neurone Disease; the use of non-invasive ventilation in the management of motor neurone disease. NICE, 2010.

4 Oliver D, Faull C. Non-invasive ventilation in amyotrophic lateral sclerosis/motor neurone disease. Minerva Pneumologica 2013;52:27-38.

5 O’Neill CL, Williams TL, Peel ET, et al. Non-invasive ventilation in motor neuron disease: an update of current UK practice. J Neurol Neurosurg Psychiatry 2012;83:371-6.
6 Hayashi K, Mochizuki Y, Nakayama Y, et al. Communication disorder in amyotrophic lateral sclerosis after ventilation-a proposal of staging and a study of predictive factor. Rinsho Shinkeigaku 2013;53:98-103.

7 Goldstein LH, Abrahams S. Changes in cognition and behaviour in amyotrophic lateral sclerosis: nature of impairment and implications for assessment. Lancet Neurol 2013;12:368-80.

8 Baxter SK, Baird WO, Thompson S, et al. The initiation of non-invasive ventilation for patients with motor neuron disease: Patient and carer perceptions of obstacles and outcomes. Amyotroph Lateral Scler Frontotemporal Degener 2013;14:105-10.

9 Lyall RA, Donaldson N, Fleming T, et al. A prospective study of quality of life in ALS patients treated with non-invasive ventilation. Neurology 2001;57:153-6.

10 Ando H, Chakrabarti B, Angus RM, et al. Experience of long-term use of non-invasive ventilation in motor neuron disease: an interpretative phenomenological analysis. BMJ Support Palliat Care 2014;4:50-6.

11 Oliver D. Ventilation in motor neuron disease: difficult decisions in difficult circumstances. Amyotroph Lateral Scler Other Motor Neuron Disord 2004;5:6-8.

12 Faull C, Rowe-Haynes C, Oliver D. The Issues for Palliative Medicine Doctors Surrounding the Withdrawal of NIV at the Request of a Patient with MND: A Scoping Study. BMJ Support Palliat Care 2014;4:43-9.

13 Strauss A, Corbin J. Basics of Qualitative Research: Grounded Theory Procedures and Techniques. London: Sage, 1990.

14 Bryman A. Social Research Methods. 2nd edn. Oxford: Oxford University Press, 2004.

15 Re B (Adult, refusal of medical treatment) [2002] EWHC 429 (Fam) 2 All ER449, Right of a patient who has capacity to refuse life-prolonging treatment

16 GMC Consent guidance: patients and doctors making decisions together. 2008 Legal Annex-Common Law. http:// www.gmc-uk.org/guidance/ethical_guidance/consent_guidance_ common_law.asp\#Refusal

17 Welie JV, Ten Have HA. The ethics of forgoing life-sustaining treatment: theoretical considerations and clinical decision making. Multidiscip Respir Med 2014;9:14.

18 Tweeddale MG. Grasping the nettle-what to do when patients withdraw their consent for treatment: (a clinical perspective on the case of Ms B). J Med Ethics 2002;28:236-7.

19 Gannon C. A request for hospice admission from hospital to withdraw ventilation. J Med Ethics 2005;31:383-4.

20 LeBon B, Fisher S. Case report: maintaining and withdrawing long-term invasive ventilation in a patient with MND/ALS in a home setting. Palliat Med 2011;25:262-5.

21 Curtis JR, Vincent JL. Ethics and end-of-life care for adults in the intensive care unit. Lancet 2010;376:1347-53.

22 Szalados JE. Discontinuation of mechanical ventilation at end-of-life: the ethical and legal boundaries of physician conduct in termination of life support. Crit Care Clin 2007;23:317-37, xi.

23 van der Hoven B, de Groot YJ, Thijsse WJ, et al. What to do when a competent ICU patient does not want to live anymore but is dependent on life-sustaining treatment? Experience from The Netherlands. Intensive Care Med 2010;36:2145-8.

24 British Broadcasting Corporation. Inside the ethics committee: withdrawing Treatment. 2011. http://www.bbc.co.uk/ programmes/b012r7jn (accessed 18 Nov 2014).

25 General Medical Council: Good Medical Practice. 2013. 